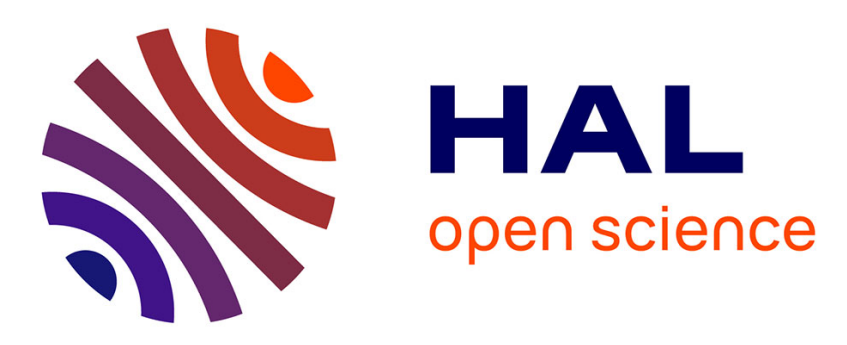

\title{
Development of seismic fragility surfaces for reinforced concrete buildings by means of nonlinear time-history analysis
}

Darius Seyedi, Pierre Gehl, John Douglas, L. Davenne, N. Mezher, S. Ghavamian

\section{To cite this version:}

Darius Seyedi, Pierre Gehl, John Douglas, L. Davenne, N. Mezher, et al.. Development of seismic fragility surfaces for reinforced concrete buildings by means of nonlinear time-history analysis. Earthquake Engineering and Structural Dynamics, 2010, 39, p. 91-108. 10.1002/eqe.939 . hal-00558781

\section{HAL Id: hal-00558781 https://hal-brgm.archives-ouvertes.fr/hal-00558781}

Submitted on 2 Feb 2011

HAL is a multi-disciplinary open access archive for the deposit and dissemination of scientific research documents, whether they are published or not. The documents may come from teaching and research institutions in France or abroad, or from public or private research centers.
L'archive ouverte pluridisciplinaire HAL, est destinée au dépôt et à la diffusion de documents scientifiques de niveau recherche, publiés ou non, émanant des établissements d'enseignement et de recherche français ou étrangers, des laboratoires publics ou privés. 
Article accepted in Earthquake Engineering \& Structural Dynamics

Final version, February 2009

\title{
Development of seismic fragility surfaces for reinforced concrete buildings by means of nonlinear time-history analysis
}

\author{
D.M. Seyedi $^{1 *}$, P. Gehl ${ }^{1}$, J. Douglas ${ }^{1}$, L. Davenne ${ }^{2}$, N. Mezher ${ }^{2}$, S. Ghavamian ${ }^{2}$ \\ ${ }^{1}$ BRGM - Development Planning and Natural Risks Division, 3 avenue Claude Guillemin, \\ BP 36009, F-45060 Orléans, France \\ ${ }^{2}$ NECS, 196 rue Houdan, F-92330 Sceaux, France
}

\begin{abstract}
:
Earthquake shaking applies complex loading to a structure. It cannot be completely characterized by a single parameter, e.g. peak ground acceleration. However, fragility curves are generally developed using a single parameter to relate the level of shaking to the expected structural damage. The main goal of this work is to use several parameters to characterize the earthquake ground motion and relate these to the expected damage. The fragility curves will, therefore, become surfaces when the ground motion is represented by two parameters. To this end, the roles of various strong-motion parameters on the induced damage in the structure are compared through nonlinear time-history numerical calculations. A robust structural model that can be used to perform numerous nonlinear dynamic calculations, with an acceptable cost, is adopted. The developed model is based on the use of structural elements with concentrated nonlinear damage mechanics and plasticity-type behavior. The relations between numerous ground-motion parameters, characterizing different aspects of the shaking, and the computed damage are analyzed and discussed. Natural and synthetic accelerograms were chosen/computed based on a consideration of the magnitude-distance ranges of design earthquakes. A complete methodology for building fragility surfaces based on damage calculation through nonlinear numerical analysis of multi-degree-of-freedom (MDF) systems is proposed. The fragility surfaces are built to represent the probability that a given damage level is reached (or exceeded) for any given level of ground motion characterized by the two chosen parameters. The results show that an increase from one to two ground-motion parameters leads to a significant reduction in the scatter in the fragility analysis and allows the uncertainties related to the effect of the second ground-motion parameter to be accounted for within risk assessments.
\end{abstract}

Keywords: seismic vulnerability, fragility surfaces, numerical structural modeling, dynamic analysis, structural damage, earthquake risk assessment

\footnotetext{
* Corresponding author: D. Seyedi, d.seyedi@ brgm.fr, Tel. +33 (0)2 386434 08, Fax: +33 (0)2 38643689
} 


\section{Introduction}

Accurate earthquake risk evaluation requires a correct estimation of the seismic hazard and a good evaluation of the seismic vulnerability of structures through an appropriate earthquake damage model. The induced aggression (e.g. caused by an earthquake) should be expressed in terms of a number of accessible and pertinent parameters for use in vulnerability analysis.

Extensive studies in the United States (e.g. HAZUS [1]) and in Europe (e.g. RISK-UE [2; 3]) have produced efficient approaches for vulnerability assessment. Such procedures consist of finding the expected damage level induced in each kind of element at risk for a given hazard level. Depending on the size of the area considered and the importance of the element at risk the method may be: statistical (semi-empirical vulnerability functions), based on simplified structural models or methods of analysis/assessment, or through direct time-history nonlinear computations.

Existing vulnerability assessment methods can be classified into these four groups [4]: empirical, judgmental, analytical and hybrid. The damage data used within these methods are, respectively: observed post-seismic surveys, expert judgment, analytical simulations or combinations of these. Each data source has associated advantages and disadvantages. A critical review of existing vulnerability functions can be found in Rossetto and Elnashai [4].

Analytical vulnerability curves adopt damage distributions simulated from the analysis of structural models under increasing earthquake loads (e.g. [5; 6]). A variety of analysis procedures have been followed, ranging from the elastic analysis of equivalent single-degreeof-freedom systems [7], adaptive pushover analysis of multistory models [6] to nonlinear time-history analyses of 3D models of RC structures [8]. The choices made for the analysis method, structural idealization, seismic hazard characterization and damage models strongly influence the derived curves and have been seen to cause significant discrepancies in seismic risk assessments made by different groups for the same location, structure type and seismicity [9].

The classical procedures are based on the study of simplified substitute structures that are not capable of accounting for the load redistribution inside structures due to local nonlinearities. The objective of damage assessment is to evaluate expected losses based on sufficiently detailed analysis and evaluation of the vulnerability characteristics at a given level of earthquake ground motions. The conditional probability that a particular building will reach a certain damage state should be determined using a fragility model. Note that in this article we reserve the use of the expression 'fragility' for this specific purpose whereas 'vulnerability' is used in a more general sense and when only the average damage level given a ground-motion level without any notion of probability.

A single ground-motion parameter (e.g. peak ground acceleration, PGA, or macroseismic intensity) cannot accurately characterize the loading applied to a given structure from an earthquake. However, in current vulnerability assessment methods earthquake hazard is often characterized by a single parameter, such as PGA or spectral displacement, SD, at the natural period of the structure, which is perhaps modified by a factor to account for earthquake duration such as in the HAZUS methodology [1]. Fragility curves are then developed by using this single parameter to relate the level of shaking to the expected damage. 
This standard method to develop fragility curves neglects the variability in the estimated damage caused by the use of a single ground-motion parameter. Current fragility curves often neglect this scatter, which means that this uncertainty cannot properly be propagated to subsequent parts of the risk analysis nor can the importance of this variability be assessed.

Recently, some efforts have been made to introduce the effect of several ground-motion parameters on the structural damage (e.g. [10; 11; 12]). Kafali and Grigoriu [11] used an alternative intensity measure expressed by two parameters: earthquake magnitude and sourceto-site distance. On this basis, they proposed fragility surfaces for single degree-of-freedom systems using simple synthetic ground motions. A vector-valued ground-motion intensity measure (IM) consisting of pseudo-spectral acceleration and some additional parameters related to shape of the response spectrum has also been investigated (e.g. [10]). Rajeev and co-workers used spectral acceleration at two different periods as the IMs [12]: the spectral acceleration (SA) at the first-mode structural period T1 is the first component of the IM vector and the second period is selected to increase the efficiency of the IM (i.e. to minimize the dispersion). With reference to an example RC-frame structure, the accuracy of prediction of the seismic risk using the considered vector IM vs. a conventional scalar IM is presented. They showed that an effective choice of the second period $\mathrm{T}_{2}$ leads to an estimate of the seismic risk to that obtained employing a scalar IM consisting of SA(T1) only, while reducing the associated dispersion in the estimate. However, for the studied example structure, the reduction is negligible in light of the effort required for switching from a scalar to a vector IM.

Although previous researchers have shown that using more than one strong-motion intensity parameter can lead to a better prediction of damage, very few have gone the extra step to develop fragility functions for various damage states explicitly involving more than one parameter and those studies that have are limited due to their use of simplistic structural models (e.g. single-degree-of-freedom systems), ground motions (e.g. stochastic timehistories) and/or damage levels (e.g. collapse or non-collapse). The main goal of the present article is to improve the representation of the strong ground motion by introducing the fragility surface concept in risk assessments for current reinforced concrete structures through nonlinear time-history analysis of MDF systems. In this approach, the shaking is characterized by two IMs. The selected IMs should be poorly correlated for efficient characterization of the shaking. On the contrary, the structural damage must be correlated to the selected parameters.

To this end, the damage level of a typical reinforced concrete structure is evaluated by the use of nonlinear numerical calculations. By considering the parts of the structure that would suffer significant damage during strong ground motions (plastic hinges), an adequate 3D nonlinear robust-yet-simplified finite element model is created to allow numerous computations. The maximum inter-story drift ratio is used to define the damage level of the studied structure. The relationships between various IMs and the computed damage are compared. Such a study can help find a small number of ground-motion parameters that lead to, when used together to characterize the shaking, the smallest scatter in the estimated damage. Fragility surfaces are then proposed for the studied structure. Note, however, that we do not propose these surfaces for use in practice since some geometrical simplifications were made to facilitate numerical calculations. In addition, only the scatter in the estimated damage level due to ground-motion variability is investigated and we assume that there is no variation in the material or geometric properties of our structure nor is there any uncertainty in the estimation of the damage level that the structure will sustain given a measure of the structural response (in our case maximum inter-storey drift). These limitations of our study would need to be considered 
when developing fragility functions to be used in practice for a set of structures. The main aim of this study is to show the advantage of using fragility surfaces developed by time-history calculations rather than curves and to suggest a methodology for their development.

\section{Models and analysis}

This section discusses the structural and material models used and the analysis conducted.

\subsection{Structural model}

The main goal of vulnerability assessment methods is to estimate the seismic response of existing buildings. For this purpose we define the structural model based on an existing building constructed in the 1970s. This is an eight-storey regular frame reinforced concrete (RC) structure as shown in Figure 1. The structural system of the building mainly consists of parallel shear walls in the $\mathrm{Y}$ direction, and $\mathrm{RC}$ beam-columns frame in the $\mathrm{X}$ direction.

The main purpose of the structural model developed for this study was not to account in detail for all mechanisms of degradation that the structure could suffer during severe ground motions but rather to develop a realistic model to be able to conduct many nonlinear calculations to demonstrate the fragility surface concept. Therefore, the modeled structure was simplified based on several considerations: the induced damage is assumed to be concentrated at the extremities of beams and columns. The failure mode is of a plastic-hinge type; shear failure may not occur. The used model does not account for phenomena such as concrete crushing or steel rebar buckling. Once the concept of fragility surfaces is demonstrated and methods for their construction are refined, our structural model may be enriched to account for degradation mechanisms such as: shear failure, rebar buckling, concrete cover spalling, axial force-moment interaction, cyclic fatigue and steel rebar debonding.

The structure is represented by a three-dimensional finite element mesh, using shells to represent slabs and walls, beams for beams and columns, and discrete rotational elements for beam/slab junctions. In the present study, slabs and shear walls are considered to remain elastic linear. As mentioned above, the only nonlinearity was represented by concentrated plastic hinges placed at the extremities of beams and columns. These were represented by discrete elements, and their characteristics were derived from the design detailing (concrete and longitudinal rebars). These elements may be used to provide rigid links, linear elastic stiffness and nonlinear connections between two nodes in any of the six degrees of freedom. In our case, only the flexural bending rotations were allowed to behave nonlinearly. The other degrees of freedom were set as rigid links. Details on the material model for this element are provided in the next section.

The building is anchored at its base, without considering any flexibility from the soil. Permanent loads were taken into account. Finally, Rayleigh damping is included in the calculation algorithm to assure a certain level of energy dissipation. The damping ratios were set at 5\% for the first two eigenfrequencies; this produces stronger damping for higher frequencies of vibration of the model.

The earthquake is applied to the structure in the $\mathrm{X}$ direction as an acceleration time-history. Only one horizontal component was used for each analysis. Calculations were carried out with Code_Aster ${ }^{\circledR}$ [13] finite element program, using the Newton-Raphson implicit algorithm. 


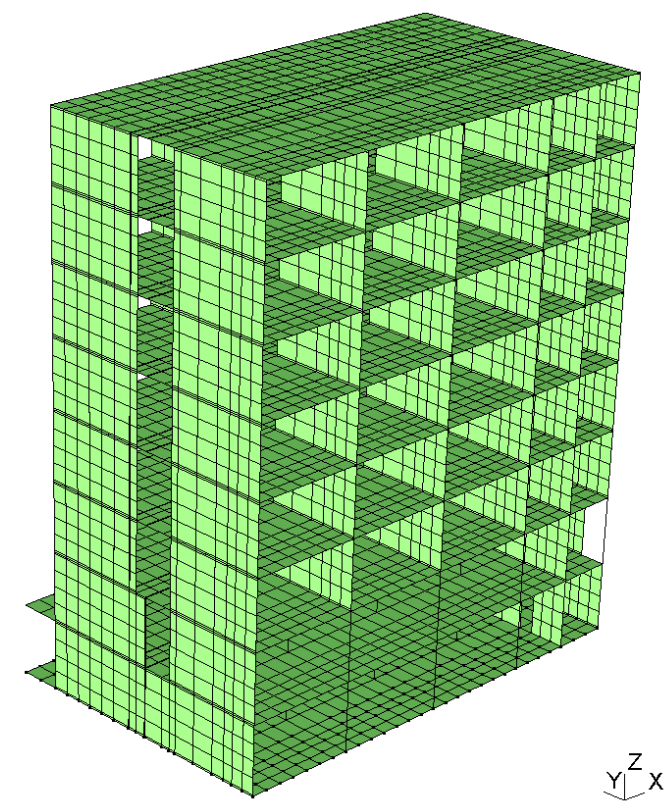

Figure 1 - Finite element mesh of the studied building

\subsection{Nonlinear material model}

Observations made of buildings that have suffered damage during past earthquakes show that well designed frame structures exhibit nonlinearities mainly through the creation of plastic hinges at the ends of beams and columns (see Figure 2). Assuming that the building chosen for the purpose of this study would behave similarly, and seeking an efficient model (see Section 2.1), discrete finite elements were placed at the ends of all beams and columns to allow the creation of plastic hinges.

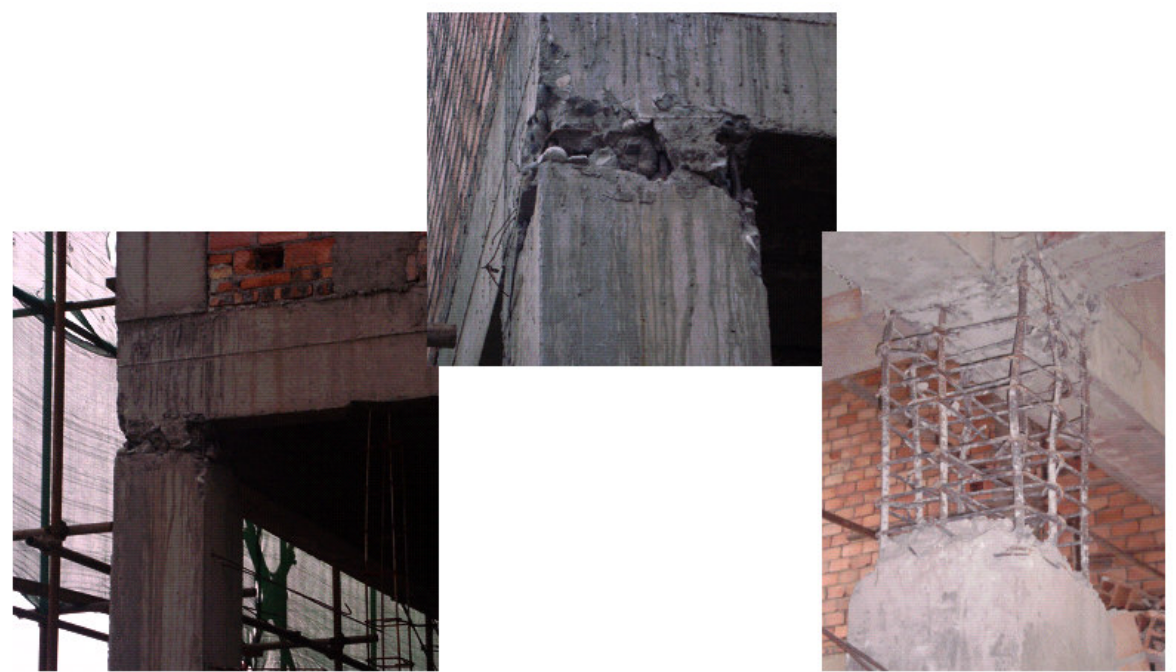

Figure 2 - Examples of damage to RC frame buildings. Photographs taken by S. Ghavamian in Dujiangyan following the 2008 Sichuan earthquake

The main features of the material model used to describe the behavior of these plastic hinges are: maximum moment capacity, isotropic strain hardening and inelastic rotation (energy dissipation). 
The formulation of the model is given below:

Yield function $f=|M|-M_{p}$.

If $\mathrm{f}<0$ the behavior remains elastic: $\dot{M}=K_{e} \dot{\theta}$.

Otherwise the evolution follows the following conditions:

$$
f=0 \text { and } \dot{f}=0, \text { with } \dot{\theta}_{p}=\dot{\lambda} \frac{\partial f}{\partial M}
$$

where $K_{e}$ denotes elastic stiffness, $F_{e}$ yield stress, $M_{p}$ yield moment, $M_{u}$ ultimate moment capacity, $n$ is a constant and:

$$
M_{p}\left(\theta_{c p}\right)=\frac{K_{e} \theta_{c p}}{\left[1+\left(\frac{K_{e} \theta_{c p}}{M_{u}}\right)^{n}\right]^{\frac{1}{n}}}
$$

where $k_{e}$ denotes the yield stiffness, $\theta_{c p}$ is the cumulated plastic rotation and $M_{u}$ the ultimate yield moment.

The behavior of the model for a cyclic loading is shown in Figure 3.

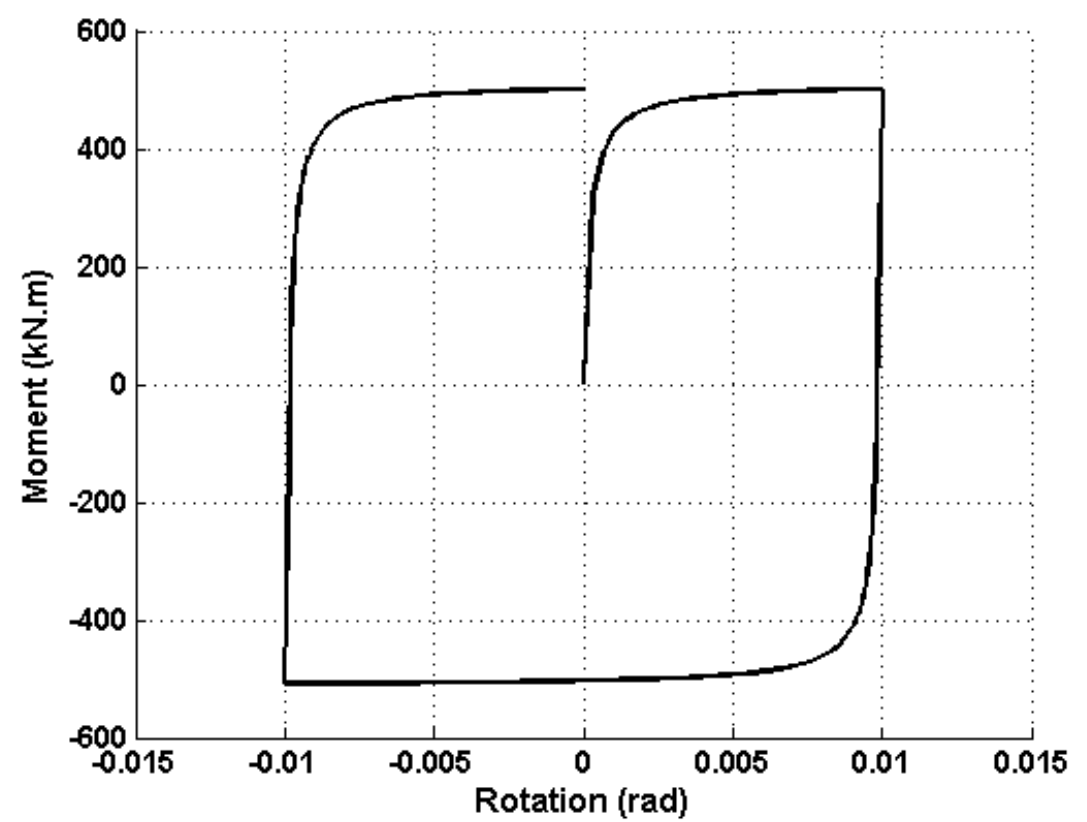

Figure 3 - Nonlinear behavior of the discrete models used to represent the formation of plastic hinges

To identify the parameters of this model, the reinforcement detailing of the cross section of each column is introduced in a RC design software package to compute the global momentrotation evolution of the element, based on the material parameters of the concrete and steel rebars. 


\section{Selection of input time-histories}

As shown by Douglas [14] input time-histories for structural analyses are often selected without considering the seismic hazard of the region of interest. In addition, it has been common to employ a small set of 'standard' time-histories (e.g. El Centro 1940) when conducting analyses even though this will underestimate the variation in possible structural response and, in addition, some of these 'standard' strong-motion records will not be appropriate for all sites due to, for example, the magnitude of the earthquake being larger than is possible in the study region [14]. For the study summarized in this article we have paid attention to the selection of time-histories that are appropriate for the seismic hazard of the region of interest and also provide an appropriate range of motions so that the possible variation in structural response is not underestimated - more details are given in [15].

To better understand the behavior of the modeled structure under earthquake loading and to investigate which characteristics (e.g. amplitude, duration or frequency content) of the ground motions are most important five sets of eight accelerograms were selected based on ideas from the theory of Design of Experiments. The procedure followed is summarized in Douglas [14] and the results obtained using these accelerograms are presented in Seyedi et al. [16]. These analyses showed that the effect of the duration of strong shaking (characterized by the interval between 5 and $95 \%$ of total Arias intensity) does not have a significant impact on the damage sustained by the studied structure. To explain this observation the following simplifications in the structural model should be noted. With respect to local structural behavior the nonlinear constitutive model does not exhibit any fatigue under reverse loading. Therefore, discrete lumped damage elements placed at the extremities of beams and columns would provide a steady capacity under constant loading. However, from a global structural point of view the evolution of damage is more or less progressive with the duration of earthquake shaking, which then induces varying patterns of load evolution at different parts of the structure. This may be interpreted as fatigue behavior, depending on the degree of regularity of the structure, possibilities of load distribution and the intensity of the ground motion (sudden appearance of damage or their smooth progression). In addition, the analysis showed that response spectral displacements at periods close to the natural period of the modeled structure are strongly correlated to the damage level. These preliminary findings were used as a basis for the more comprehensive analysis summarized here.

\subsection{Selection based on seismic hazard of the French Antilles}

In this article it is assumed that the analyzed structure is located in the French Antilles (Guadeloupe and Martinique), which is a region affected by both crustal and subduction (interface: shallow-dipping thrust events and intraslab: deep, generally normal-faulting, events) earthquakes. Therefore, a set of strong-motion records were compiled that is consistent with the seismicity of this region.

A magnitude-distance-earthquake-type filter is applied to a large database of strong-motion records from various regions of the world (mainly the Mediterranean region, the Middle East, western North America, central America, Japan and Taiwan) to exclude records from magnitudes and distances that are not possible for the French Antilles. This selection has been made by considering the seismogenic sources in the region in terms of their location and the magnitude range of the earthquake they produce. Also records from small earthquakes and great distances were excluded since such weak motions will not lead to significant damage for the structure analyzed here. For this study, the seismogenic sources for the region of the French Antilles proposed by Geoter [17] were used to select the records. Based on this study these selection criteria were adopted: 
Crustal earthquakes: $5.5 \leq \mathrm{M}_{\mathrm{w}} \leq 7.5,0 \leq \mathrm{R}_{\mathrm{JB}} \leq 30 \mathrm{~km}$ and $0 \leq \mathrm{h} \leq 30 \mathrm{~km}$

Interface earthquakes: $5.5 \leq \mathrm{M}_{\mathrm{w}} \leq 8.0,0 \leq \mathrm{R}_{\mathrm{JB}} \leq 50 \mathrm{~km}$ and $0 \leq \mathrm{h} \leq 50 \mathrm{~km}$

Intraslab earthquakes: $5.5 \leq \mathrm{M}_{\mathrm{w}} \leq 7.5,0 \leq \mathrm{R}_{\mathrm{JB}} \leq 50 \mathrm{~km}$ and $50 \leq \mathrm{h} \leq 150 \mathrm{~km}$

where $M_{w}$ is the moment magnitude, $R_{J B}$ is the distance to the surface projection of the rupture (Joyner-Boore distance) and $\mathrm{h}$ is the focal depth.

\subsection{Further selection to limit number of records required}

The first step leads to a preliminary selection of many hundreds of strong-motion records. Due to the long run times of the finite element modeling of the structural response it was necessary to optimize the number of accelerograms selected. On the other hand a minimum number of accelerograms covering the range of ground motions that could be experienced in the region of interest must be selected. From the pre-selected dataset (Section 3.1), we retain only those natural accelerograms with ground-motion characteristics that cover useful ranges of possible motions (i.e. we discard the accelerograms that have the same characteristics as previously selected records). In a later stage we introduce some synthetic accelerograms to complete this dataset for poorly sampled ground-motion ranges.

To select a limited set of records that still cover the range of possible ground motions two strong-motion intensity parameters that are poorly correlated were chosen and then records are selected from intervals defined by ranges of these parameters. The two parameters selected are: elastic response spectral displacement at $1 \mathrm{~s}$ for $5 \%$ damping, $\mathrm{SD}(1 \mathrm{~s})$, and relative significant duration (defined by the interval between 5 and $95 \%$ of total Arias intensity), RSD. The ranges of observed $\mathrm{SD}(1 \mathrm{~s})$ and RSD were divided into 20 logarithmical spaced intervals (i.e. $20 \times 20=400$ bins in total) and one record was randomly selected from each bin. The aim of this selection is to choose the minimum number of records that covers the range of possible ground motions. Due to a non-uniform distribution with respect to $\mathrm{SD}(1 \mathrm{~s})$ and $\mathrm{RSD}$ records were only found in 129 out of the 400 bins: few strong-motion records were found that had both long durations and high $\mathrm{SD}(1 \mathrm{~s})$ values. In addition to these 129 records analyses had already been run using the 40 records selected during the preliminary analyses discussed above. Therefore, in total 169 natural accelerograms were used as input to the structural modeling to construct the fragility surfaces.

\subsection{Use of simulated strong-motion records}

Since the whole range of possible motions is not covered by the selected natural accelerograms it was decided to augment the input time-history dataset with records simulated using the non-stationary stochastic method of Pousse et al. [18], which is an extension of the procedure of Sabetta \& Pugliese [19]. In the technique of Pousse et al. empirical groundmotion prediction equations (GMPEs) for a handful of characteristics of shaking (peak ground acceleration, duration, Arias intensity and central frequency) are used to shape and scale a Fourier spectrum defined from a seismological-based source model and an envelope function consistent with seismological considerations (e.g. P and $\mathrm{S}$ phase arrival times). This envelope and the estimated Fourier spectrum are then used to shape white noise in the frequency and time domains to produce realistic strong-motion records. Advantages of this method are [20]: its rapidity (hundreds of records can be generated in a few minutes); its simplicity (since it does not require complex source, path and site modeling); and that the time-histories produced include ground-motion variability (an important consideration when conducting structural modeling). 
The computer code of Pousse et al. was used to simulate time-histories with $\mathrm{M}_{\mathrm{w}}$ between 4.5 and 7.5 in steps of 0.5 , epicentral distances between 10 and $100 \mathrm{~km}$ in steps of $10 \mathrm{~km}$ and for all five site classes of Eurocode 8. The GMPEs developed by Pousse et al. were used and their distributions were truncated at three standard deviations in order not to simulate non-physical ground motions. Since the GMPEs of Pousse et al. were developed from K-Net data from Japan, like the French Antilles an area close to subduction zones, these equations are suitable for ground-motion simulations in our study.

We confirmed that the ground motions simulated using the technique of Pousse et al. led to damage levels consistent with those found using natural accelerograms (Figure 4). In total, 571 synthetic accelerograms were used in addition to the 169 natural records previously selected. An advantage of using these simulated ground motions over the natural accelerograms is that the structural modeling was faster due to the generally shorter length of the records.

\section{Selection of strong-motion parameters}

The goal of this section is to find a small number of ground-motion parameters that lead to, when used together to characterize the shaking, the smallest scatter in the estimated damage, computed using the structural model presented in Section 2. Orthogonal parameters are sought that characterize different aspects of the shaking, e.g. the amplitude, frequency content and duration, so that the fewest number of parameters is needed. A balance needs to be struck between introducing more parameters, thereby leading to a reduction in the scatter in the fragility curve, and the uncertainty in the estimation of these parameters for given earthquake scenarios.

Problems associated with the choice of parameters for ground-motion and damage characterization can be identified in almost all existing vulnerability relationships [4]. The parameter chosen to represent ground motion in the construction of vulnerability curves must be both representative of the damage potential of earthquakes and easily quantifiable from knowledge of the earthquake characteristics. Many existing vulnerability assessment methods use macroseismic intensities to characterize the seismic aggression (e.g. ATC-13 [21], RISKUE [2;3] and [22; 23]) but intensity is a subjective and discrete scale and, in addition, it cannot be accurately predicted using GMPEs. In this study, we selected several strong-motion intensity parameters that can be well estimated through GMPEs and that are likely to have a strong influence on the building response.

As noted in Section 3, the plastic hinge model used in this study does not take into account any phenomena like fatigue that depend on the number of cycles. Hence, we do not examine the damage level with indicators such as the Park \& Ang index [24], which relies on hysteretic energy and accumulated plasticity. Therefore, it is more suitable to evaluate the damage level by measuring the peak displacements of the structural elements during the simulation. The inter-storey drift ratio (ISDR), i.e. the relative peak displacement between two consecutive floors, is a widely-used indicator to measure the behavior of the structure. We evaluate the ISDR at each storey and retain the highest value to give an overall idea of the building damage level. The 740 selected accelerograms discussed in Section 3 were used to run the nonlinear structural analysis. Table 1 presents the linear best-fit equations connecting the inter-storey drift ratio and the IMs. The choice of the periods at which the spectral displacements were examined was guided by eigenvalue analysis of the modeled building. The two main eigenperiods along the $\mathrm{X}$ direction (the direction where the seismic input is 
applied) were found to be 1.26 and $0.41 \mathrm{~s}$ and, hence, SDs at these two periods were considered as IMs.

Table 1 - Correlation between various IMs (x) and the building inter-stroy drift ratio (ISDR). The equation reported is derived through linear regression.

\begin{tabular}{|l|l|l|l|}
\hline Parameter & Description & $\begin{array}{l}\text { Equation } \\
(\text { ISDR=mx+c) }\end{array}$ & $\begin{array}{l}\text { Correlation } \\
\text { coefficient } \mathbf{R}^{\mathbf{2}}\end{array}$ \\
\hline SD(1.26s) & $\begin{array}{l}\text { Spectral displacement at the period } \\
\text { of the first mode }\end{array}$ & $5.6025 \mathrm{x}-0.025$ & 0.837 \\
\hline SD $(0.41 \mathrm{~s})$ & $\begin{array}{l}\text { Spectral displacement at the period } \\
\text { of the second mode }\end{array}$ & $20.99 \mathrm{x}-0.0084$ & 0.650 \\
\hline PGA & Peak ground acceleration & $0.1239 \mathrm{x}+0.0213$ & 0.578 \\
\hline AI & Arias intensity & $0.1506 \mathrm{x}+0.1479$ & 0.565 \\
\hline AUD & $\begin{array}{l}\text { Absolute uniform duration (based } \\
\text { on a threshold on 0.03g) }\end{array}$ & $0.0834 \mathrm{x}+0.0454$ & 0.532 \\
\hline RSD & $\begin{array}{l}\text { Relative significant duration (based } \\
\text { on the interval between 5 and 95\% } \\
\text { Arias intensity) }\end{array}$ & $-0.0025 \mathrm{x}+0.3045$ & 0.305 \\
\hline RUD & $\begin{array}{l}\text { Uniform relative duration (based on } \\
\text { a threshold of 10\% PGA) }\end{array}$ & $-0.0027 \mathrm{x}+0.2972$ & 0.003 \\
\hline NC & $\begin{array}{l}\text { Equivalent number of effective } \\
\text { cycles (Rainflow method) }\end{array}$ & $0.0191 \mathrm{x}+17.784$ & 0.000 \\
\hline
\end{tabular}

As shown in Table 1, the parameters that are related to the relative duration of the signal or the number of cycles do not have any influence on the building response. This is unsurprising since the plastic hinge model does not take phenomena such as fatigue into account. On the other hand, spectral displacements at the natural structural periods are strongly correlated with the ISDR (Figure 4).
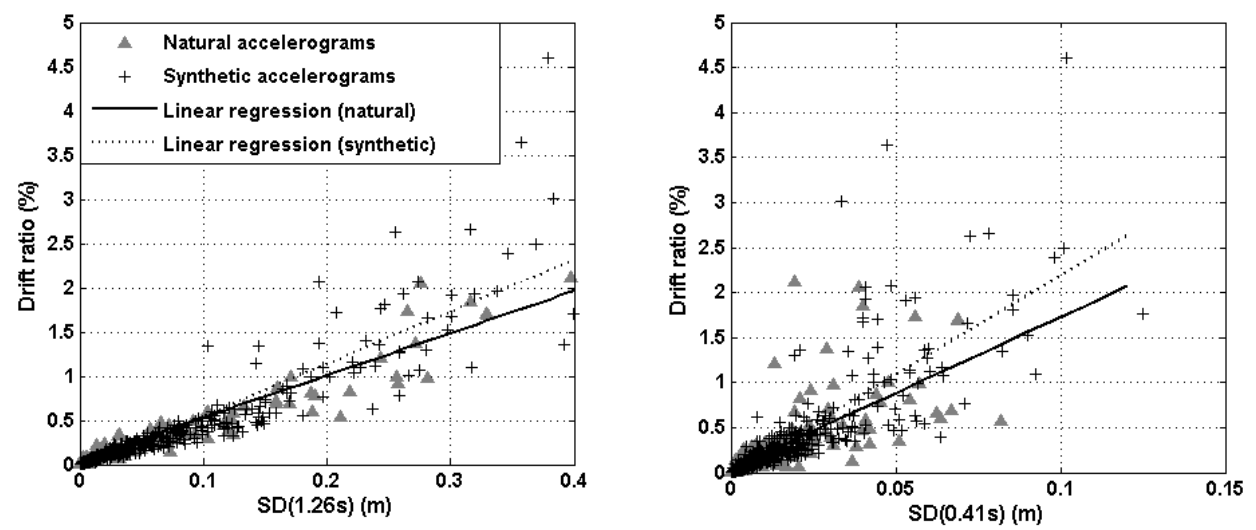

Figure 4 - Linear regression between the spectral displacements at the first two natural structural periods and the inter-storey drift ratio. Black squares (and solid lines) refer to natural accelerograms whereas gray triangles (and dashed lines) are from synthetic records.

\section{Fragility surfaces}

This section presents the fragility surfaces developed for the prediction of the damage level. 


\subsection{Choice of parameters}

The previous parametric study led to the choice of the SDs at the periods of the first and second modes as useful variables for constructing the fragility surfaces (see Table 1). Many input time-histories are required to construct reliable fragility surfaces. Considering a graph with the two selected strong-motion IMs on the two axes, the chosen time-histories should cover in a homogeneous manner the dataspace of possible motions. This is not really true for the two selected parameters (Figure 5). Nevertheless these two parameters are sufficiently uncorrelated (correlation coefficient of 0.83 ) to be used to build a fragility surface, e.g. for a $\mathrm{SD}(1.26 \mathrm{~s})$ of $0.01 \mathrm{~m}$ Figure 5 shows that $\mathrm{SD}(0.41 \mathrm{~s})$ can range between roughly $6 \times 10^{-4} \mathrm{~m}$ and $0.02 \mathrm{~m}$. Only some extreme situations (i.e. low $\mathrm{SD}(1.26 \mathrm{~s})$ and very high $\mathrm{SD}(0.41 \mathrm{~s})$ and vice versa) are not represented; these situations are not, in fact, realistic for earthquake shaking.

One potential drawback in using $\mathrm{SD}\left(\mathrm{T}_{2}\right)$ as an IM for the construction of fragility surfaces is that the period of the second mode $\left(\mathrm{T}_{2}\right)$ is not commonly measured (or calculated) or reported for most RC buildings. Therefore, it could be difficult to construct or select appropriate fragility surfaces requiring an estimate of $T_{2}$ for a population of buildings, which in general will have unknown $\mathrm{T}_{2} \mathrm{~s}$. However, since $\mathrm{T}_{2}$ can be easily computed by eigenvalue analysis from numerical structural models (or measured in the field using ambient- or forced-vibration measurements) it should be possible to develop guidance on the expected range of $T_{2}$ for typical RC buildings, which could be used if and when fragility functions are developed using IMs based on $\mathrm{T}_{2}$.

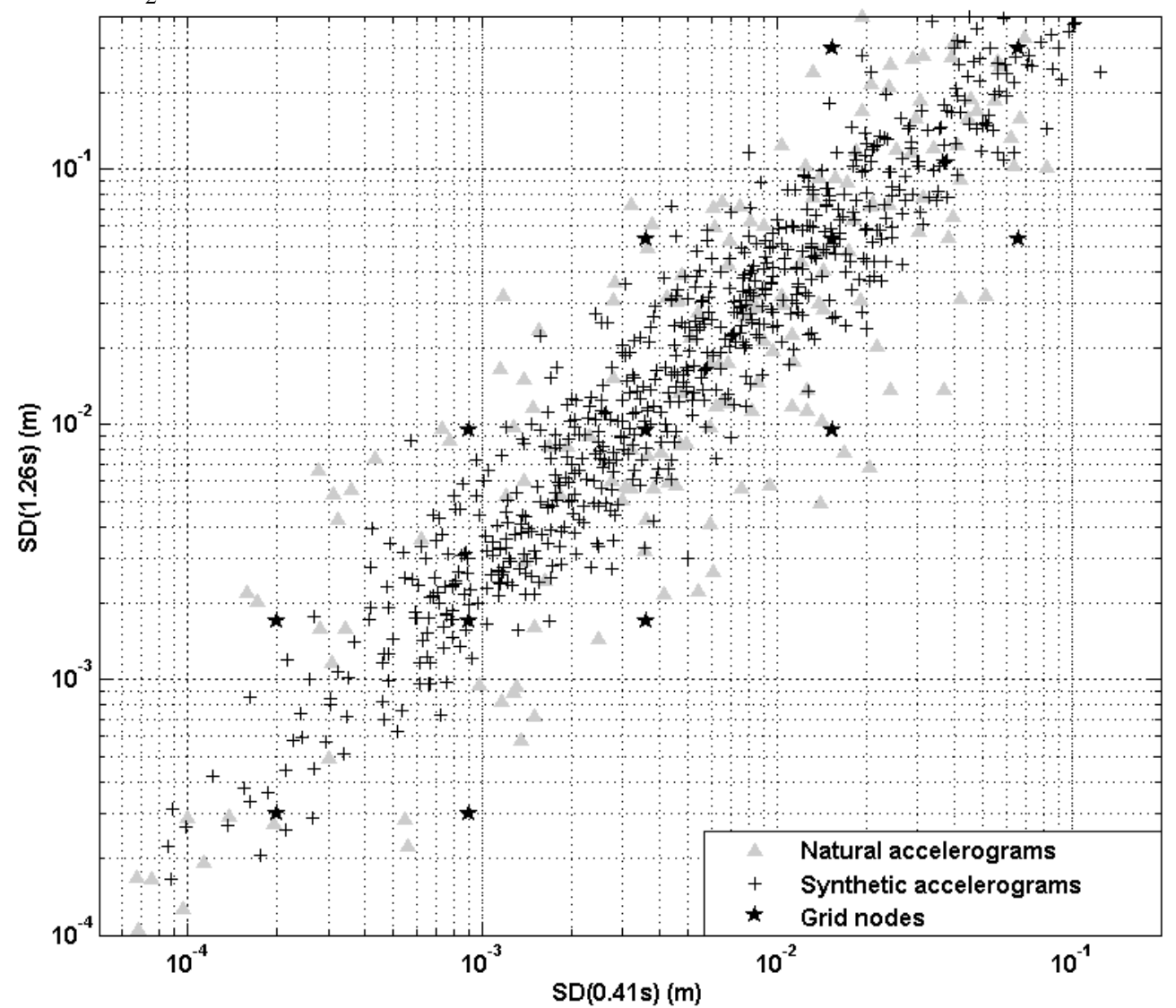

Figure 5 - Distribution of selected time-histories in $S D(0.41 s)-S D(1.26 s)$ space. The crosses (and the gray triangles) represent the synthetic (and the natural) accelerograms respectively. The stars denote the nodes of the grid (i.e. the points in the neighborhood of which the damage probability is evaluated). 


\subsection{Damage analysis}

Based on thousands of observations Rossetto and Elnashai [4] developed empirical functions that correlate the ISDR and the damage level for different types of European RC buildings. Depending on the type of RC structure, relations convert the ISDR into a homogenized reinforced concrete damage index $\left(\mathrm{DI}_{\mathrm{HRC}}\right)$, which can then be linked to the EMS-98 [25] damage scale. Table 2 represents the relationships proposed by Rossetto and Elnashai [4]. The correlation between $\mathrm{DI}_{\mathrm{HRC}}$ and EMS-98 damage level is shown in Table 3 [4]. Given the model of the studied structure we use the relation for non-ductile moment-resisting frames to estimate the damage level of the structure based on the ISDR.

Table 2 - Relationships between inter-storey drift ratio (ISDR) and $\mathrm{DI}_{\mathrm{HRC}}$ [4]

\begin{tabular}{|l|l|l|}
\hline Structural system & Proposed relationship & $\mathbf{R}^{\mathbf{2}}$ \\
\hline Non-ductile moment-resisting frames & $\mathrm{DI}_{\mathrm{HRC}}=34.89 \ln (\mathrm{ISDR})+39.39$ & 0.991 \\
\hline In-filled frames & $\mathrm{DI}_{\mathrm{HRC}}=22.49 \ln (\mathrm{ISDR})+66.88$ & 0.822 \\
\hline Shear-wall systems & $\mathrm{DI}_{\mathrm{HRC}}=39.31 \ln (\mathrm{ISDR})+52.98$ & 0.985 \\
\hline General structures & $\mathrm{DI}_{\mathrm{HRC}}=27.89 \ln (\mathrm{ISDR})+56.36$ & 0.760 \\
\hline
\end{tabular}

Table 3 - Correlation between the damage index DI and the EMS 98 damage level [4]

\begin{tabular}{|l|l|}
\hline DI $_{\mathrm{HRC}}$ value & EMS 98 damage level \\
\hline $\mathrm{DI}<0$ & D0 \\
\hline $0<\mathrm{DI}<30$ & $\mathrm{D} 1$ \\
\hline $30<\mathrm{DI}<50$ & $\mathrm{D} 2$ \\
\hline $50<\mathrm{DI}<70$ & D3 \\
\hline $70<\mathrm{DI}<100$ & D4 \\
\hline $\mathrm{DI}>100$ & D5 \\
\hline
\end{tabular}

\subsection{Development of fragility surfaces}

The following procedure has been developed to construct the fragility surfaces. For the two chosen strong-motion intensity parameters (here, $\mathrm{SD}\left(\mathrm{T}_{1}\right)$ and $\mathrm{SD}\left(\mathrm{T}_{2}\right), \mathrm{T}_{1}$ and $\mathrm{T}_{2}$ being the first $(1.26 \mathrm{~s})$ and second $(0.41 \mathrm{~s})$ natural periods of the building) 25 couples (nodes) of coordinates $\left(x_{i}, y_{i}\right)$ have been selected so as to cover the space defined by the parameters $x$ and $y$, where $x$ and $y$ are $\mathrm{SD}(0.41 \mathrm{~s})$ and $\mathrm{SD}(1.26 \mathrm{~s})$, respectively (see Figure 5).

For each of the 740 accelerograms used in the simulations, we seek the closest nodes $\left(x_{i}, y_{i}\right)$ on the grid. To avoid bias due to differently-scaled parameters the distances between the recorded SDs and the nodes are first normalized. For each node, the probability of exceeding the damage level $\mathrm{D}_{\mathrm{k}}$ is evaluated using the following equation:

$$
P\left(d>D_{k} \mid\left(x_{i}, y_{i}\right)\right)=N\left(D_{k},\left(x_{i}, y_{i}\right)\right) / N_{t o t}\left(x_{i}, y_{i}\right)
$$

where $N_{t o t}\left(x_{i}, y_{i}\right)$ is the number of points which are closest to the node $\left(x_{i}, y_{i}\right)$.

This approach should enable us to obtain 25 probability values for each damage level $D_{k}$ and then through linear interpolation we could obtain the fragility surfaces. However, as shown in Figure 5 not all the 25 nodes have sufficient points close enough to produce an accurate surface. Hence, it was decided to consider only nodes that are in the neighborhood of at least five points. Applying this constraint we only obtain a dozen acceptable probabilities, which is 
not enough to draw a smooth surface through simple interpolation. Therefore we chose to apply the following approach:

- a linear interpolation is performed between the dozen nodes;

- "slices" [by considering $\mathrm{SD}(0.41 \mathrm{~s})$ as constant] are extracted from the surface, for many values of $\mathrm{SD}(0.41 \mathrm{~s})$;

- "slices" are extracted along the other axis [i.e. SD(1.26s)];

- a regression is performed, to find $a, b, c$ and $d$, for each slice, using equation 5 (where erf is the error function). This equation is adapted from the shape of commonly used fragility curves, which usually correspond to a normal distribution cumulative function:

$$
y(x)=a \cdot\left[1+\operatorname{erf}\left(\frac{\ln (x)-\ln (b)}{c}\right)\right]+d
$$

- the analytical equations are plotted to obtain a smooth surface [each point of the surface is a mean between a curve along $\mathrm{SD}(0.41 \mathrm{~s})$ and a curve along $\mathrm{SD}(1.26 \mathrm{~s})]$.

Figure 6 shows the calculated fragility surfaces for four different damage levels: D1 to D4. Each surface represents the conditional probability of reaching or exceeding $D_{k}$ damage state " $k$ " for each given value of parameters $\mathrm{SD}(1.26 \mathrm{~s})$ and $\mathrm{SD}(0.41 \mathrm{~s})$.
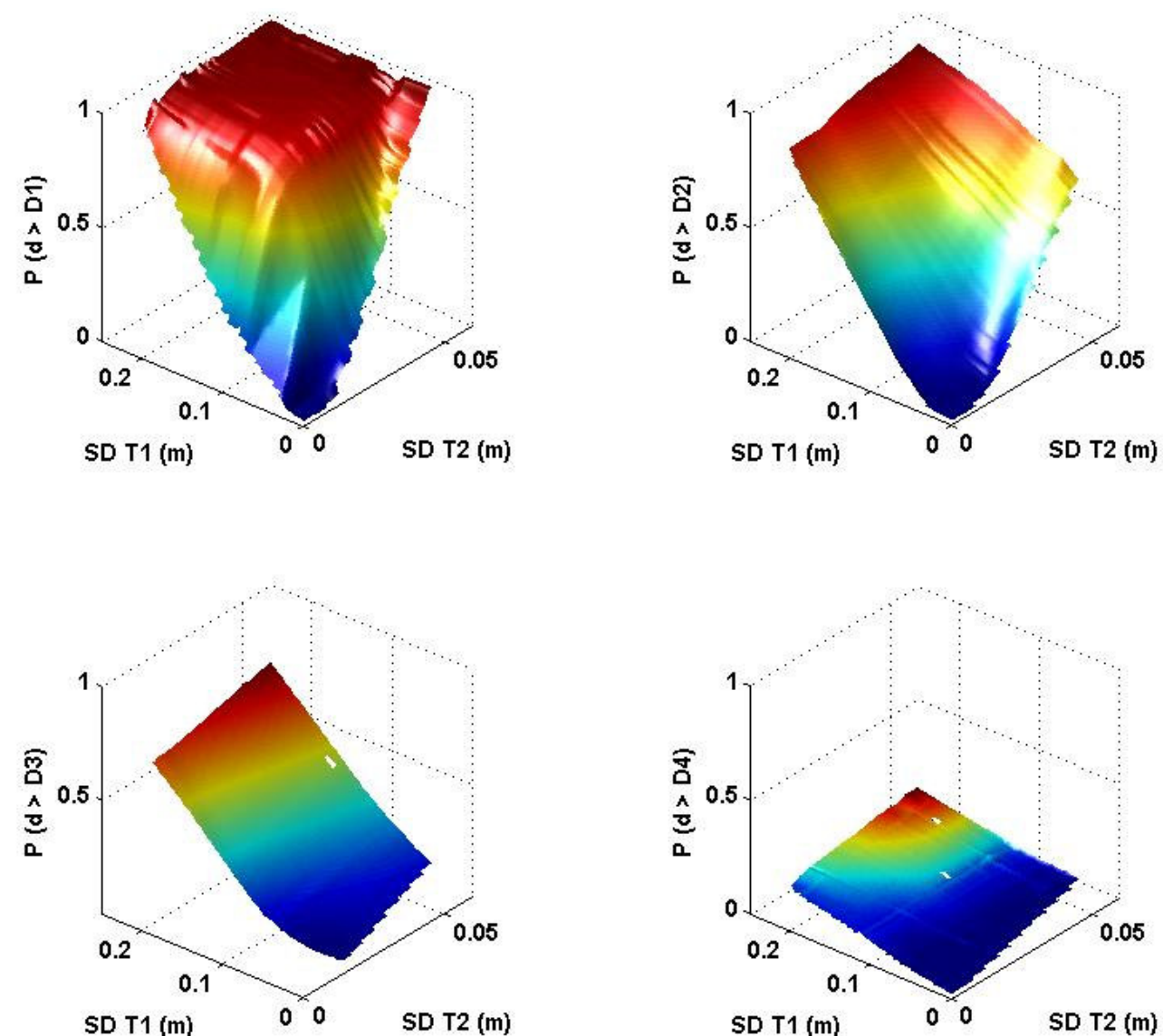

Figure 6 - Fragility surfaces of the studied building for four damage levels (based on EMS 98). The parameters are spectral displacements at $T_{1}$ and $T_{2}$, the periods corresponding to the main eigenmodes of the building in the $\mathrm{X}$ direction. 
These surfaces can be visualized as fragility curves by projecting the surfaces onto the $\mathrm{SD}(1.26 \mathrm{~s})$ or $\mathrm{SD}(0.41 \mathrm{~s})$ planes (Figure 7 , Figure 8 ). These figures demonstrate the wide variation that can exist between fragility curves based on only one strong-motion intensity parameter.

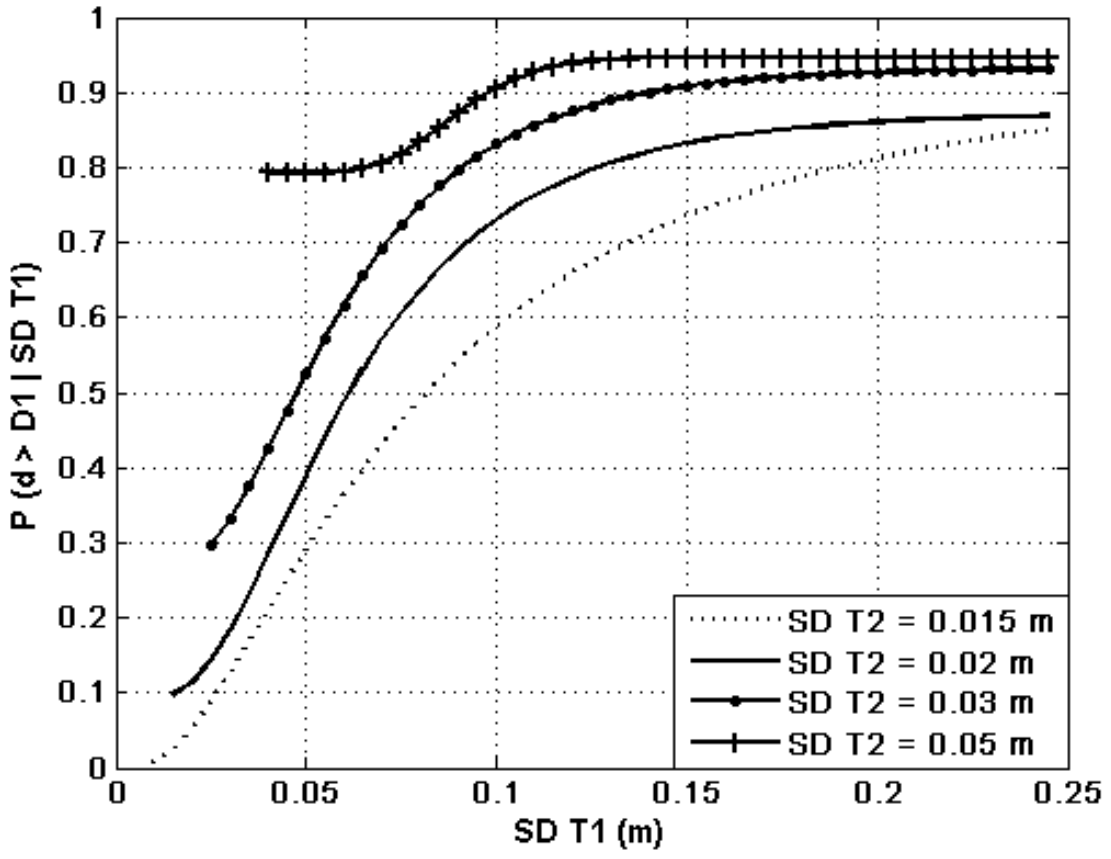

Figure 7 - Fragility curves with spectral displacement at period $T_{1}$. The curves are plotted as "slices" of the fragility surface for different values of $\operatorname{SD}\left(T_{2}\right)$. Note that the slices have been slightly smoothed and they are only plotted where they are sufficiently constrained by the analysis.

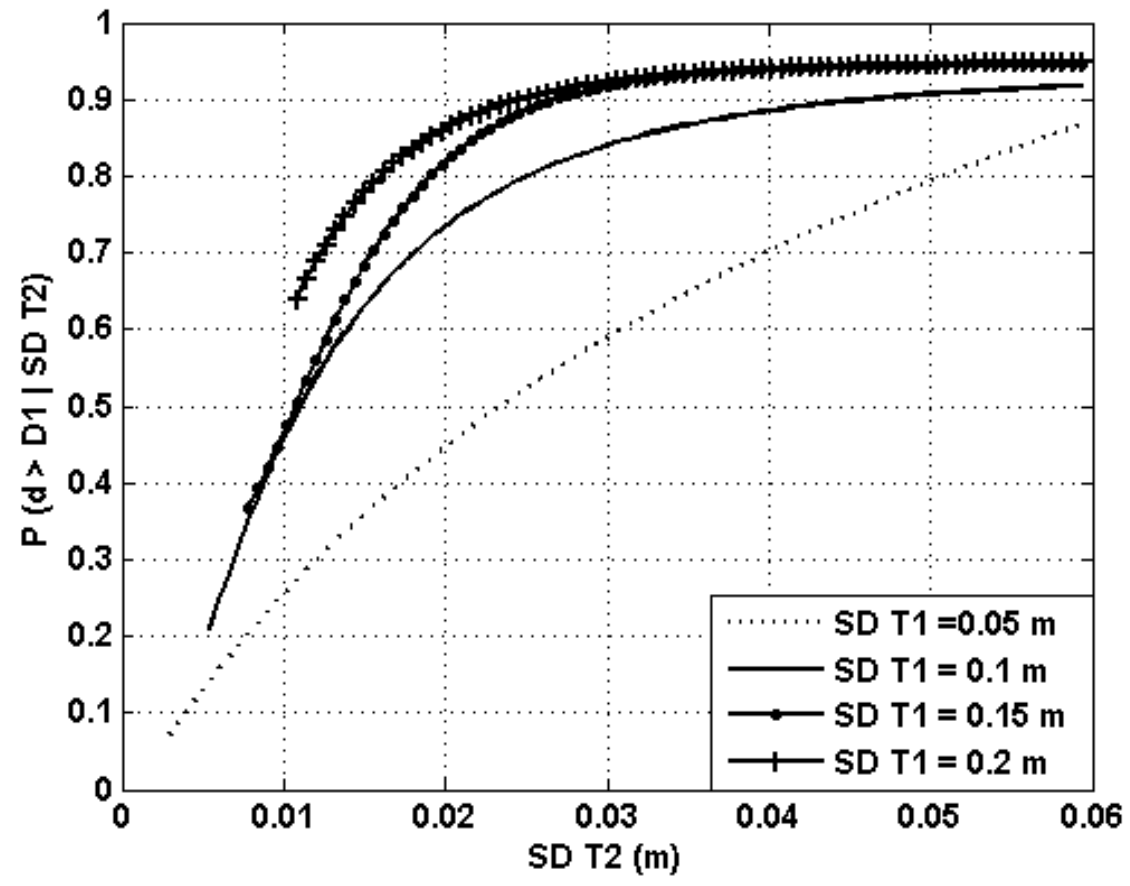

Figure 8 - Fragility curves with spectral displacement at period $T_{2}$. The curves are plotted as "slices" of the fragility surface for different values of $\operatorname{SD}\left(T_{1}\right)$. Note that the slices have been slightly smoothed and they are only plotted where they are sufficiently constrained by the analysis. 
Figure 7 and Figure 8 demonstrate the prominent role that could be played by fragility surfaces in risk analysis. Considering only one intensity measure parameter, e.g. $\operatorname{SD}\left(\mathrm{T}_{1}\right)$, we could build an average curve that does not incorporate the variability in ground motions as measured by another parameter, e.g. SD(T2). It can be seen (Figure 7) that there can be a discrepancy of up to $50 \%$ between two curves (probability of $30 \%$ for $\operatorname{SD}\left(\mathrm{T}_{2}\right)=0.015 \mathrm{~m}$ and $80 \%$ for $\mathrm{SD}\left(\mathrm{T}_{2}\right)=0.05 \mathrm{~m}$ for an $\mathrm{SD}\left(\mathrm{T}_{1}\right)$ of $\left.0.05 \mathrm{~m}\right)$.

The obtained fragility surfaces are compared with the conventional fragility curves considering only one intensity measure parameter on Figure 9 where the dotted lines represent the fragility curves. These curves were computed using the method developed by Shinozuka et al. [26], which expresses the fragility curve in the form of a two-parameter lognormal distribution function:

$$
F(x)=\phi\left[\frac{\ln (x)-\ln (\alpha)}{\beta}\right]
$$

where $x$ represents the studied parameter (in this case $\operatorname{SD}\left(\mathrm{T}_{1}\right)$ or $\operatorname{SD}\left(\mathrm{T}_{2}\right)$ ), and $\Phi$ the standardized normal distribution function. The two parameters $\alpha$ and $\beta$ represent the median and the lognormal standard deviation respectively and are computed so as to maximize the likelihood function [27], given by equation 7 .

$$
M=\prod_{k=1}^{N}\left[F\left(x_{k}\right)\right]^{y_{k}}\left[1-F\left(x_{k}\right)\right]^{1-y_{k}}
$$

where $\mathrm{N}$ is the total number of simulations, $\mathrm{x}_{\mathrm{k}}$ the $\mathrm{SD}$ (either at $\mathrm{T}_{1}$ or $\mathrm{T}_{2}$ ) of the $\mathrm{k}$-th accelerogram, and $y_{k}$ is equal to 1 or 0 , whether the structure has reached the given damage state or not (realization from a Bernoulli experiment). Table 4 gives the values of the parameters $\alpha$ and $\beta$ for each dotted curve on Figure 9.

Table 4 - Parameters of the equation for each fragility curve

\begin{tabular}{|l|c|c|}
\hline & $\boldsymbol{\alpha}$ & $\boldsymbol{\beta}$ \\
\hline SD(1.26s) (Figure 7) & 0.0721 & 0.2753 \\
\hline SD(0.41s) (Figure 8) & 0.0190 & 0.4014 \\
\hline
\end{tabular}



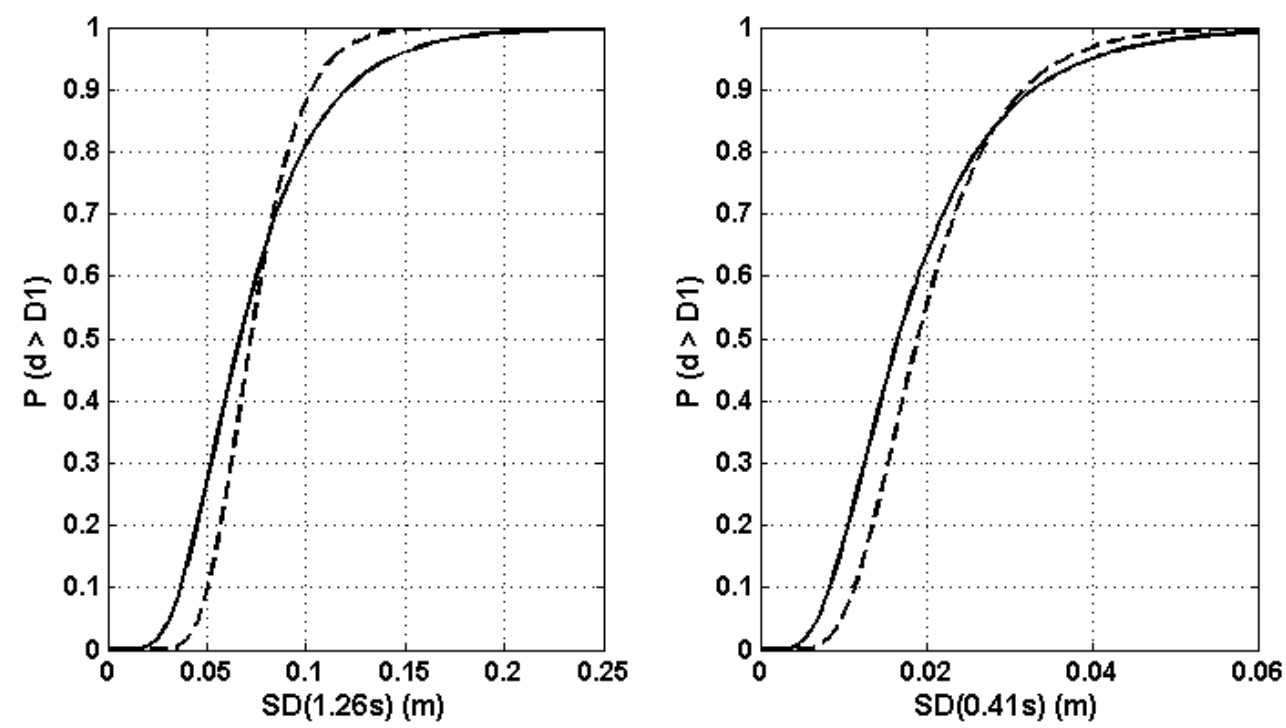

Figure 9 - Comparison between fragility surfaces and fragility curves $\left(D_{k}=D 1\right)$. The solid line corresponds to a diagonal cut of the fragility surface. The dashed line represents the analytical function calculated by equation 6 .

On Figure 9 the solid line corresponds to a diagonal cut of the calculated fragility surface. This cut was made along a linear equation connecting $\mathrm{SD}(\mathrm{T} 1)$ and $\mathrm{SD}(\mathrm{T} 2)$ derived from Figure 5, i.e. it accounts for the observed correlation between $\operatorname{SD}\left(\mathrm{T}_{1}\right)$ and $\operatorname{SD}\left(\mathrm{T}_{2}\right)$. The comparison shows that a fragility curve constructed by a standard method and considering only one parameter at a time gives results close to those obtained from a fragility surface when two parameters are well correlated (along a diagonal cut, $\mathrm{SD}\left(\mathrm{T}_{1}\right)$ and $\mathrm{SD}\left(\mathrm{T}_{2}\right)$ vary in the same manner). For other combinations of $\mathrm{SD}\left(\mathrm{T}_{1}\right)$ and $\mathrm{SD}\left(\mathrm{T}_{2}\right)$, e.g. a relatively high $\mathrm{SD}\left(\mathrm{T}_{1}\right)$ and a relatively low $\mathrm{SD}\left(\mathrm{T}_{2}\right)$ (which may occur at a soft soil site that amplifies long-period motions), a standard fragility curve can not represent the effect of the second parameter on the seismic behavior of the structure. The main advantage of fragility surfaces is that the variability of structural fragility due to a second IM can be estimated in contrast to when fragility curves are used. This enables us to correctly propagate the uncertainties due to this variability in risk assessments. Thanks to the fragility surfaces, it should be possible to conduct more accurate risk analyses, which we plan to test in a future study.

\section{Conclusions}

The current methods used to model the seismic vulnerability of structures (i.e. through fragility curves) often represent the ground motion by a single parameter (e.g. PGA). However, a single parameter cannot fully represent the effect of an earthquake on the seismic response of the structure. It is expected that an increase from one to two ground-motion parameters would lead to a significant reduction in the scatter in the fragility function.

To this end, a nonlinear structural model to calculate the induced damage in a reinforced concrete structure has been developed. Several parameters were chosen to represent the characteristics of the earthquake shaking. Five sets, each containing eight strong-motion records, were used, so that each set could represent the various combinations of the tested parameters. A strong correlation between $\mathrm{SD}\left(\mathrm{T}_{1}\right), \mathrm{SD}\left(\mathrm{T}_{2}\right)$ (where $\mathrm{T}_{1}$ and $\mathrm{T}_{2}$ are the periods of the first and second modes) and the maximum inter-story drift ratio (as the damage measure) is observed. The obtained results indicate that the parameters related to structural dynamic 
characteristics (e.g. SD) are more suitable for fragility analysis this structural model, which does not include fatigue effects.

Based on the obtained results, fragility surfaces that relate the strong-motion intensity (represented by two parameters) to the possible damage of the structure are developed. The spectral displacements at the two first modes of structure are chosen to represent the strong ground motion. A comparison between different profiles obtained by the obtained fragility surfaces shows the significant role of the second parameter in calculated damage probability. If only one parameter, e.g. $\mathrm{SD}\left(\mathrm{T}_{1}\right)$ is considered, we can build an average curve that does not incorporate the variability due to the other characteristics of the ground motions. Fragility surfaces provide a robust way to propagate the effects of this variability in seismic risk assessments.

As discussed in the Introduction, the analysis presented here is simplified to enable us to conduct many hundreds of nonlinear time-history analyses in a reasonable time. Because of a lack of field data some of the properties used in our simulations have been estimated. Therefore, results of this study should only be considered qualitatively since the quantitative results are sensitive to the assumed material properties and construction details. In the future, a more detailed damage analysis should be performed in order to properly evaluate the role of all parameters. In this view, the effect of each parameter on several damage indicators (e.g. energy-based indicators and combination measures) can be investigated. The strong-motion parameters must be chosen for each structural type as a manner to incorporate the dynamic response of the structure.

\section{Acknowledgements}

The work presented in this article has been supported by the French Research National Agency (ANR) through the CATTEL-2005 program (project 'Seismic vulnerability of structures: A damage mechanics approach' (VEDA) under grant number ANR-05-CATT017). We thank the providers of the strong-motion and the structural data used. The authors wish also to thank Prof. Hormoz Modaressi and Mr Florent De Martin for useful discussions. In addition, we thank Guillaume Pousse for sending us his computer program to simulate strong-motion records using his method. Finally, we thank Dr Tiziana Rossetto and an anonymous reviewer for their detailed reviews of an earlier version of this article, which led to significant improvements.

\section{References}

1. FEMA, HAZUS earthquake loss estimation methodology: User's manual. Federal Emergency Management Agency, Washington DC, USA., 1999.

2. Lagomarsino, S. and Giovinazzi, S., Macroseismic and mechanical models for the vulnerability assessment of current buildings. Bull. Earthquake Eng. 2006; 4: 415-443.

3. Mouroux, P. and Le Brun, B., Presentation of RISK-UE project. Bull. Earthquake Eng. 2006; 4: 319-321.

4. Rossetto, T. and Elnashai, A., Derivation of vulnerability functions for European-type RC structures based on observational data. Engineering Structures 2003; 25: 1241-63.

5. Saxena, V., Deodatis, G., Shinozuka, M. and Feng, M., Development of fragility curves for multi-span reinforced concrete bridges. In Proceedings of International Conference on Monte Carlo Simulation, 2000

6. Rossetto, T. and Elnashai, A., A new analytical procedure for the derivation of displacement-based vulnerability curves for populations of RC structures. Engineering Structures 2005; 27: 397-409. 
7. Mosalam, K., Ayala, G., White, R. and Roth, C., Seismic fragility of LRC frames with and without masonry infill walls. J. Earthquake Engg. 1997; 1: 693-719.

8. Singhal, A. and Kiremidjian, A., A method for earthquake motion damage relationships with application to reinforced concrete frames. Research Report NCEER-97-0008 State University of New York at Buffalo: National Center for Earthquake Engineering, 1997.

9. Strasser, F. O., Bommer, J. J., Sesetyan, K., Erdik, M., Çagnan, Z., Irizarry, J., Goula, X., Lucantoni, A., Sabetta, F., Bal, I. E., Crowley, H. and Lindholm, C., A comparative study of european earthquake loss estimation tools for a scenario in Istanbul. J. Earthquake Engg. 2008; 12(1): 246-256.

10. Baker, J. W. and Cornell, C. A., A vector-valued ground motion intensity measures consisting of spectral acceleration and epsilon. Earthquake Engng Struct. Dyn. 2005; 34: 1193-1217.

11. Kafali, C. and Grigoriu, M., Seismic fragility analysis: Application to simple linear and nonlinear systems. Earthquake Engng Struct. Dyn. 2007; 36: 1885-1900.

12. Rajeev, P., Franchin, P. and Pinto, P. E., Increased accuracy of vector-IM-based seismic risk assessment? J. Earthquake Engg. 2008; 12: 11-124.

13. Code_Aster Code d'Analyses des Structures et Thermomécanique pour Etudes et Recherches, 2008 http://www.code-aster.org, EDF R\&D

14. Douglas, J., Strong-motion records selection for structural testing. 1st European Conference on Earthquake Engineering and Seismology, ECEES, Geneva, Switzerland, 2006

15. Douglas, J., Selection of strong-motion records for use as input to the structural models of VEDA. Rapport final BRGM/RP-54584-FR BRGM, 2006.

16. Seyedi, M., Gehl, P., Davenne, L., Ghavamian, S., Mezher, N., Douglas, J., Martin, F. D. and Modaressi, H., Numerical modelling of the influence of earthquake strong-motion characteristics on the damage level of a reinforced concrete structure. Colloque AFPSO7, Paris, 2007

17. Martin, C., Combes, P., Secanell, R., Lignon, G., Fioravanti, A., Carbon, D., Monge, O. and Grellet, B., Revision du zonage sismique de la France : Etude Probabiliste, Rapport de Phase 3. Report GTR/MATE/0701-150, Affaire no. 1601, 2002.

18. Pousse, G., Bonilla, L. F., Cotton, F. and Margerin, L., Non stationary stochastic simulation of strong ground motion time histories including natural variability: Application to the K-net Japanese database. Bulletin of Seismological Society of America 2006; 96(6): 21032117, DOI697 10.1785/0120050134.

19. Sabetta, F. and Pugliese, A., Estimation of response spectra and simulation of nonstationary earthquake ground motions. Bulletin of Seismological Society of America 1996; 86(2): 337-352.

20. Douglas, J. and Aochi, H., A survey of techniques for predicting earthquake ground motions for engineering purpose. Surveys in Geophysics 2008; 29(3): 187-220.

21. ATC-40, Seismic evaluation and retrofit of concrete buildings. Applied Technology Concil Report, 1996.

22. Spence, R. J. S., Coburn, A. W. and Pomonis, A., Correlation of ground motion with building damage: the definition of a new damage based seismic intensity scale. In: Proceedings of the 10th World Conference Of Earthquake Engineering, Rotterdam, AA Balkema, 1992 1, 551-556.

23. Orsini, G., A model for buildings' vulnerability assessment using the parameterless scale of seismic intensity (PSI). Earthquake Spectra 1999; 15: 463-83.

24. Park, Y. and Ang, A., Mechanistic Seismic Damage Model for Reinforced Concrete. J. Structural Engg. 1985; 111: 722-739.

25. Conseil de l'Europe, European macroseismic scale 1998 (EMS-98). Chaier du Centre Européan de Géodynamique et de Séismologie. G. Grünthal (Eds.) 199815. 
26. Shinozuka, M., Feng, Q., Lee, J. and Naganuma, T., Statistical analysis of fragility curves. J. Engineering Mech., ASCE 2000; 126(12): 1224-1231.

27. Shinozuka, M., Statistical analysis of bridge fragility curves. Proceedings of the US-Italy Workshop on Protective Systems for Bridges, New-York, April 26-28., 1998 